\title{
( \\ CONSCIOUS SEDATION FOR MIDDLE EAR SURGERIES: COMPARISON BETWEEN PROPOFOL AND MIDAZOLAM WITH RESPECT TO HEMODYNAMIC EFFECTS
}

\section{Dr. Firdos Girkar Dr. Priyanka Jagavkar* \\ ABSTRACT}

Senior resident, Terna Medical College Navi Mumbai, India. Assistant Professor, K. J. Somaiya Hospital, Mumbai, India. *Corresponding Author Background And Aims: Middle ear surgeries can be done under local anesthetic infiltration and titrated dose of sedation. Use of supplemental intravenous sedative hypnotic drugs for these surgeries under local anesthesia can enhance patient comfort and increase acceptance of this technique. Our study was aimed to compare Propofol and Midazolam in equipotent doses for conscious sedation in middle ear surgeries

Methods And Material: After approval from the Institutional Ethics committee, 60 patients from ASA grade 1 and 2 scheduled for middle ear surgery (Tympanoplasty, mastoidectomy) under local anesthesia were randomly allocated into two groups to receive either Propofol (Group I) or Midazolam (Group II) for conscious sedation. Both the groups received premedication and sedation with $1.5 \mathrm{mcg} / \mathrm{kg}$ Fentanyl, Group 1 received Inj. Propofol bolus dose of $0.5-1 \mathrm{mg} / \mathrm{Kg} \mathrm{I.V}$, followed by infusion at the rate of $1.5-4.5 \mathrm{mg} / \mathrm{kg} / \mathrm{hour}$, to attain a sedation score of 3 and additional bolus doses were given as and when required to maintain a sedation score of 3 .

Group 2 received Inj. Midazolam bolus dose 0.03 to $0.05 \mathrm{mg} / \mathrm{kg} \mathrm{I.V} \mathrm{followed} \mathrm{by} \mathrm{infusion} \mathrm{at} \mathrm{the} \mathrm{rate} \mathrm{of} 0.03$ to $0.06 \mathrm{mg} / \mathrm{kg} / \mathrm{hour}$ to attain a sedation score of 3 and additional bolus doses as and when required to maintain a sedation score of 3 . All the patients in both the groups received oxygen by nasal prongs at the flow rate of $4 \mathrm{~L} / \mathrm{min}$ from the start of sedation. Heart rate, systolic blood pressure, diastolic blood pressure, respiratory rate, oxygen saturation was noted at basal level and at an interval of 2 minutes and later every 5 mins for 30 mins then every 15 mins till end of surgery. Result: The results were analyzed using student's 't' test and chi square test wherever appropriate.

Results: Pulse rate at 30th minute of sedation was not significantly different from the basal value among both the groups. Mean systolic blood pressure (SBP) in Propofol group was $121.33 \mathrm{mmHg}$ and $117.27 \mathrm{mmHg}$ among Midazolam group at basal which was comparable and the difference was not significant. Mean diastolic blood pressure was $78.47 \mathrm{mmHg}$ in Propofol group and $78.07 \mathrm{mmHg}$ among Midazolam group at basal which was comparable and the difference was not significant. Mean respiratory rate (breaths $/ \mathrm{min}$ ) among Propofol and Midazolam group were 16.83 and 16.70 respectively at basal which was comparable and the difference was not significant. Mean arterial oxygen saturation (\%) among Propofol and Midazolam group were and 98.0 and 98.07 respectively at basal which was comparable and the difference was not significant.

Conclusions: After the start of sedation mean diastolic blood pressure did not show any significant change in both the groups throughout the procedure. After the start of sedation mean respiratory rate and arterial oxygen saturation did not show any significant change in both the groups. Both Propofol and Midazolam are equally safe with respect to hemodynamic effects when used in titrated doses.

\section{KEYWORDS : Conscious Sedation, Midazolam, Middle Ear Surgeries, Propofol, Hemodynamic Effects, Aerosol generation}

\section{INTRODUCTION:}

Surgical Otologic procedures such as uncomplicated middle ear surgery like Tympanoplasty, Mastoidectomy and Stapedectomy can be performed using local anesthetic infiltration and carefully titrated sedation. Its advantages include the avoidance of certain risks inherent in general anesthesia like aerosol generation, middle ear pressure changes associated with use of nitrous oxide $\left(\mathrm{N}_{2} \mathrm{O}\right)$, airway obstruction, pulmonary aspiration and avoidance of operating theatre pollution, the provision of good postoperative analgesia and the benefits in certain preexisting medical conditions. Use of supplemental intravenous sedative hypnotic drugs for surgery under local anesthesia can enhance patient comfort and increase acceptance of this technique. However, to preserve the benefits of the local anesthetic technique, recovery must be rapid and clearheaded with freedom from minor postoperative sequelae.

These procedures are generally not painful after adequate local anesthetic infiltration, but discomfort may occur from lying still on operating table with head and neck turned to the opposite side of the surgery. Patients should be able to understand, communicate and remain co-operative to the extent that they can hold still, especially during microscopic middle ear surgery. Patient's co-operation is frequently required for assessment of facial nerve injury/palsy after infiltration, during the procedure and post operatively.

The anesthetic management of these patients include intravenous administration of analgesic and sedative agents along with local anesthetic infiltration to produce conscious sedation, the goal being to have a calm, co-operative, comfortable patient and not to over sedate, creating an obtunded patient out of touch with the surrounding.

Propofol is the most frequently used intravenous anesthetic today. Prompt recovery without residual sedation and low incidence of nausea and vomiting make propofol well suited to ambulatory conscious sedation techniques. Midazolam an imidazobenzodiazepine derivative is utilized as premedicant, sedative and an anesthesia induction agent. For conscious sedation and anxiolysis Midazolam is used intravenously either alone or in combination with an opiate agonist to enhance patient comfort for surgery under local anesthesia. It is used for short diagnostic endoscopic procedure like upper GI endoscopy, bronchoscopy, cystoscopy, cardiac catheterization, coronary angiography, computerized tomography. It is used in dentistry and ICU patient sedation. Midazolam has also been used along with regional anesthesia as sedative adjunct.

\section{MATERIALSAND METHODS:}

After approval from the Institutional Ethics Review Board, written informed consent was obtained from 60 patients scheduled for middle ear surgery (Tympanoplasty, Mastoidectomy) under local anesthesia. Patients were randomly allocated into two groups to receive either Propofol (Group I) or Midazolam (Group II) for conscious sedation.

After arrival of the patient to operation theatre consent was rechecked, starvation confirmed and monitors such as pulse oximeter, blood pressure cuff were attached and vital parameters pulse rate, blood pressure, respiratory rate and peripheral oxygen saturation were noted. An intravenous line was secured with an $20 \mathrm{G}$ canula and Ringer's Lactate drip started. Each patient received Inj Glycopyrolate $0.2 \mathrm{mg}$ min 30 mins prior to shifting to operating room, Inj Ondansetron 4mg iv and Inj. Fentanyl $1.5 \mathrm{mcg} / \mathrm{Kg} \mathrm{I} . \mathrm{V}$ on operating table.

Heart rate, blood pressure, electrocardiogram, respiratory rate and arterial oxygen saturation were monitored at 2 and 5 minutes after the start of sedative infusion and there after every 5 minutes for the first half an hour and then every 15 minutes till the end of the procedure. All patients received oxygen at 4 -litres/min by nasal prongs. Any untoward effects of Propofol or Midazolam such as pain on injection, apnea, drop in oxygen saturation, abnormal movements, hiccups, rash, nausea and vomiting were noted.

Local anesthetic, lignocaine adrenaline $2 \%(1: 2,00,000)$ (volume of 7 $10 \mathrm{cc}$ ) was infiltrated at the operative site when patient was in plane 3 of the Five Pont Sedation Scale (eyes closed but arousable). 


\section{Statistical Analysis:}

In this study for each parameter of both the groups, group I (Propofol) and group II (Midazolam), mean and standard deviations were calculated. To find out the significant difference between the groups, students unpaired ' $t$ ' test was used and to see the change within a group paired ' $t$ ' test was used. The Chi-square test was used for qualitative data.

\section{RESULTS}

Table 1: Demographic Characteristics Of Patients

\begin{tabular}{|l|l|l|}
\hline \multicolumn{1}{|c|}{ Parameters } & Propofol & Midazolam \\
\hline Number of patients & 30 & 30 \\
\hline Mean Age (yrs) & $29.33 \pm 6.68$ & $28.80 \pm 9$. \\
\hline Mean weight (kg) & $51.40 \pm 8.12$ & $54.27 \pm 9.47$ \\
\hline Sex & $14(46.7)$ & $19(63.3)$ \\
Male & $16(53.3)$ & $11(36.7)$ \\
Female & $29(96.7)$ & $27(90.0)$ \\
\hline ASA status & $01(3.3)$ & $3(10.0)$ \\
Grade I & & $25(83.3)$ \\
Grade II & $20(66.7)$ & $05(16.7)$ \\
\hline Surgery & $10(33.3)$ & \\
Tympanoplasty &
\end{tabular}

(Values expressed as mean $\pm \mathrm{SD}$ or percentage)

Above table 1 reveals that the mean age of the patients in Propofol group was 29.33 years and 28.80 years among Midazolam group which is comparable and the difference is not statistically significant. The Mean weights of the patients among the two groups were comparable. $46.7 \%$ of the total cases were male in Propofol group and $63.3 \%$ in Midazolam group. ASA grades (American Society of Anesthesiologist) were also comparable between the two groups. Percentage of tympanoplasty surgeries were more among Midazolam group i.e. $83.3 \%$ as compared to $66.7 \%$ in Propofol group but the difference is not significant.

Table 2: Comparison Of Changes In Pulse Rate Between Propofol And Midazolam

\begin{tabular}{|l|l|l|}
\hline \multirow{2}{*}{ Duration (mins) } & \multicolumn{2}{|l|}{ Pulse rate (beats/min) (mean \pm SD) } \\
\cline { 2 - 3 } & Propofol & Midazolam \\
\hline Basal & $88.90 \pm 13.75$ & $83.43 \pm 11.36$ \\
\hline 2 & $87.23 \pm 16.49$ & $84.63 \pm 10.76$ \\
\hline 5 & $87.73 \pm 12.58$ & $84.83 \pm 12.37$ \\
\hline 10 & $* 102.43 \pm 16.26$ & $* 95.73 \pm 15.90$ \\
\hline 15 & $* 105.80 \pm 17.71$ & $* 98.90 \pm 17.0$ \\
\hline 20 & $* 106.30 \pm 15.98$ & $* 98.43 \pm 16.34$ \\
\hline 25 & $96.60 \pm 11.45$ & $92.90 \pm 13.47$ \\
\hline 30 & $91.17 \pm 12.03$ & $88.10 \pm 11.67$ \\
\hline
\end{tabular}

(By Student “t”" Test) $\mathrm{p}<0.05$ significant; $\mathrm{P}>0.05$ not significant.

Above table 2 shows that mean pulse rate among Propofol and Midazolam group were 88.90 /minute and 83.43 /minute respectively at basal which was comparable and difference was not significant. After the start of sedation at 2 and 5 minutes mean pulse rate did not show significant difference in both the groups. But at $10^{\text {th }}$ minute mean pulse rate had an increase of $15.2 \%$ in Propofol group and $14.74 \%$ in Midazolam group which is comparable between the two groups, but significantly different from the basal values in both the groups. At the end of 30 minutes from start of sedation mean pulse rate had an increase of $2.69 \%$ in Propofol group and 5.63\% in Midazolam group from the basal value which was comparable between the two groups and also within the same group to the basal value.

Table 3: Comparison Of Changes In Systolic Blood Pressure (SBP) Between Propofol And Midazolam

\begin{tabular}{|l|l|l|}
\hline \multirow{2}{*}{ Duration (mins) } & \multicolumn{3}{|l|}{ SBP $(\mathbf{m m H g}$ ) (mean \pm SD) } \\
\cline { 2 - 3 } & Propofol & Midazolam \\
\hline Basal & $121.33 \pm 10.61$ & $117.27 \pm 11.67$ \\
\hline 2 & $118.53 \pm 10.13$ & $113.20 \pm 10.95$ \\
\hline 5 & $116.80 \pm 9.39$ & $112.47 \pm 12.67$ \\
\hline 10 & $122.47 \pm 9.0$ & $117.67 \pm 13.29$ \\
\hline 15 & $122.47 \pm 9.0$ & $120.07 \pm 12.57$ \\
\hline 20 & $121.20 \pm 8.77$ & $118.20 \pm 12.10$ \\
\hline 25 & $118.0 \pm 8.47$ & $116.73 \pm 11.77$ \\
\hline 30 & $117.13 \pm 7.27$ & $116.33 \pm 11.27$ \\
\hline
\end{tabular}

(By Student " $\mathrm{t}$ ” Test) $\mathrm{p}<0.05$ significant; $\mathrm{P}>0.05$ not significant.
Above table 3 shows Mean systolic blood pressure in Propofol group is $121.33 \mathrm{mmHg}$ and $117.27 \mathrm{mmHg}$ in Midazolam group at basal which was comparable and difference was not significant. After the start of sedation mean Systolic BP has a fall of 3.7\% among Propofol group as compared to $4.1 \%$ among Midazolam group which was comparable and difference was not significant. Mean systolic blood pressure did not show any significant change in both the groups.

Table 4: Comparison Of Changes In Respiratory Rate Between Propofol And Midazolam

\begin{tabular}{|l|l|l|}
\hline \multirow{2}{*}{ Duration (mins) } & \multicolumn{3}{|l|}{ Respiratory rate (breaths/min) (mean \pm SD) } \\
\cline { 2 - 3 } & Propofol & Midazolam \\
\hline Basal & $16.83 \pm 1.02$ & $16.70 \pm 1.24$ \\
\hline 2 & $15.80 \pm 0.96$ & $15.97 \pm 1.25$ \\
\hline 5 & $15.73 \pm 1.11$ & $15.60 \pm 1.28$ \\
\hline 10 & $17.27 \pm 1.34$ & $17.27 \pm 1.68$ \\
\hline 15 & $17.37 \pm 1.59$ & $17.30 \pm 1.53$ \\
\hline 20 & $16.93 \pm 1.70$ & $17.03 \pm 1.94$ \\
\hline 25 & $16.67 \pm 1.60$ & $17.13 \pm 1.91$ \\
\hline 30 & $16.53 \pm 1.78$ & $16.93 \pm 2.03$ \\
\hline
\end{tabular}

(By Student “ $t$ " Test) $\mathrm{p}<0.05$ significant; $\mathrm{P}>0.05$ not significant.

Above table 4 shows that mean respiratory rate was 16.83 /minute in Propofol group and 16.70/minute in Midazolam group which was comparable and the difference was not significant. After the start of sedation mean respiratory rate did not show any significant change in both the groups.

Table 5: Comparison Of Changes In Arterial Oxygen Saturation $\left(\mathrm{SpO}_{2} \%\right)$ Between Propofol And Midazolam

\begin{tabular}{|l|l|l|}
\hline \multirow{2}{*}{ uuration (mins) } & \multicolumn{2}{|l|}{ Arterial oxygen saturation (\%) (mean \pm SD) } \\
\cline { 2 - 3 } & Propofol & Midazolam \\
\hline Basal & $98.0 \pm 0.45$ & $98.07 \pm 0.58$ \\
\hline 2 & $97.90 \pm 0.66$ & $97.80 \pm 0.55$ \\
\hline 5 & $97.90 \pm 0.66$ & $98.0 \pm 0.59$ \\
\hline 10 & $98.20 \pm 0.66$ & $98.40 \pm 0.86$ \\
\hline 15 & $98.53 \pm 0.63$ & $98.60 \pm 0.81$ \\
\hline 20 & $98.80 \pm 0.66$ & $98.63 \pm 0.76$ \\
\hline 25 & $98.87 \pm 0.68$ & $98.73 \pm 0.64$ \\
\hline 30 & $98.73 \pm 0.64$ & $98.90 \pm 0.55$ \\
\hline
\end{tabular}

(By Student “ $t$ " Test) $p<0.05$ significant; $p>0.05$ not significant.

Above Table 5 reveals that mean arterial oxygen saturation was $98.0 \%$ in Propofol group and $98.07 \%$ among Midazolam group at basal which was comparable and the difference was not significant. After the start of sedation mean arterial oxygen saturation did not show any significant change in both the groups.

\section{DISCUSSION}

After the administration of Propofol or Midazolam for conscious sedation, vital parameters such as heart rate (HR) systolic blood pressure (SBP), diastolic blood pressure (DBP), respiratory rate (RR), arterial oxygen saturation $\left(\mathrm{SpO}_{2}\right)$ and electrocardiogram (ECG) were recorded at 2 and 5 minutes and thereafter every 5 minutes for the first half an hour and then every 15 minutes till the end of the procedure.

There was no significant change in mean pulse rate within both Propofol and Midazolam groups from the start of sedation to $5^{\text {th }}$ minute. At $10^{\text {th }}$ minute, there was a significant increase in the pulse rate as compared to the basal value. This increase in the pulse rate may be due to an endogenous sympathoadrenal stress response to needle prick of local anesthetic infiltration or due to absorption of exogenous epinephrine added to the local anesthetic solution. Local anesthetic (lignocaine $2 \%$ with adrenaline $(1: 2,00,000)$ infiltration was done after $5^{\text {th }}$ minute but before $10^{\text {th }}$ minute of the start of sedation. Pulse rate at $30^{\text {th }}$ minute of sedation was not significantly different from the basal value among both the groups (Table 2).

Donlon JV et al. ${ }^{(1)}$ studied plasma catecholamine levels during local anesthesia for cataract operation. The purpose of the study was to determine whether (1) there is hemodynamically significant uptake of exogenous epinephrine following eyelid infiltration and retrobulbar block (2) patients undergoing this procedure manifest elevated endogenous plasma non-epinephrine levels. They found that even after premedication with Meperidine $0.7 \mathrm{mg} / \mathrm{kg}$ IM and Promethazine $0.4 \mathrm{mg} / \mathrm{kg}$ IM an hour before operation, most of the patients showed a 
significant elevation in plasma epinephrine and nor-epinephrine levels following eye lid infiltration and retrobulbar block injection with a total of $10-12 \mathrm{ml}$ of $2 \%$ lignocaine with $1: 2,00,000$ adrenaline. The mean 2-min value and mean 7-min value for plasma epinephrine were found to be statistically significant from control value.

\section{Systolic Blood Pressure (SBP):}

Mean systolic blood pressure in Propofol group was $121.33 \mathrm{mmHg}$ and $117.27 \mathrm{mmHg}$ among Midazolam group at basal which was comparable and the difference was not significant (Table 3). After the start of sedation mean systolic blood pressure had a fall of $3.7 \%$ among Propofol as compared to $4.1 \%$ among Midazolam group which was comparable and the difference was not significant. Mean systolic blood pressure did not show any significant change in both the groups throughout the procedure. Mean diastolic blood pressure was $78.47 \mathrm{mmHg}$ in Propofol group and $78.07 \mathrm{mmHg}$ among Midazolam group at basal which was comparable and the difference was not significant. After the start of sedation mean diastolic blood pressure did not show any significant change in both the groups throughout the procedure.

\section{Heart Rate:}

At $10^{\text {th }}$ minute mean pulse rate had an increase of $15.2 \%$ in Propofol group and $14.74 \%$ in Midazolam group which is comparable between the two groups, but significantly different from the basal values in both the groups.

Mackenzie $\mathrm{N}$ et al. ${ }^{2}$ found no change in heart rate and arterial pressure with use of Propofol in sub anesthetic doses for sedation as an adjunct to spinal anesthesia as compared to the awake state.

Fanard L et al. ${ }^{3}$ found no change in heart rate in the two groups, but found significant, although transient decrease in arterial blood pressure with use of both drugs. This may be due to the use of high bolus dose of $1.49 \mathrm{mg} / \mathrm{kg}$ of Propofol and $0.05 \mathrm{mg} / \mathrm{kg}$ of Midazolam.

White PF et al. ${ }^{4}$ found no statistically significant difference between Propofol and Midazolam infusion with respect to heart rate and mean arterial pressure. Crawford $\mathrm{M}$ et al. ${ }^{5}$ found no adverse effects on arterial pressure and heart rate between Propofol and Midazolam infusion in their study.

Mean respiratory rate (breaths/min) among Propofol and Midazolam group were 16.83 and 16.70 respectively at basal which was comparable and the difference was not significant (Table 4).

Mean arterial oxygen saturation (\%) among Propofol and Midazolam group were and 98.0 and 98.07 respectively at basal which was comparable and the difference was not significant (Table 5).

After the start of sedation mean respiratory rate and arterial oxygen saturation did not show any significant change in both the groups.

All the patients in both the groups received oxygen by nasal prongs at the flow rate of $4 \mathrm{~L} / \mathrm{min}$ from the start of sedation.

Mackenzie $\mathrm{M}$ et al. ${ }^{2}$ in their study, noted that airway maintenance was excellent with no instances of airway obstruction, cough, laryngospasm, respiratory depression or apnea with use of Propofol infusion in sub anaesthetic doses for sedation as an adjunct to spinal anaesthesia.

Fanard $\mathrm{L}$ et al. ${ }^{3}$ in their study, noted that two patients became apneic after giving bolus (induction) dose of Propofol $1.49 \mathrm{mg} / \mathrm{kg}$ and there was a mean decrease in arterial oxygen saturation of $4 \%$ compared to $2.67 \%$ in Midazolam group. Respiratory obstruction occurred in one patient who received Propofol. These effects were mainly due to the use of high bolus dose of Propofol.

Crawford $\mathrm{M}$ et al. ${ }^{5}$ in their study compared Midazolam with Propofol for sedation in outpatient bronchoscopy and noted decrease in oxygen saturation during the procedure in all patients in both the groups. 4/21 patients in each group suffered desaturation after sedation before the introduction of the bronchoscope. There was no statistically significant difference in mean oxygen saturation between the two groups at the time of recovery.

Rosa G et al. ${ }^{6}$ in their study, noted that repeated small doses of Propofol $(0.3-0.6 \mathrm{mg} / \mathrm{kg})$ caused no significant variations in respiratory rate, minute volume, tidal volume, inspiratory and expiratory time, airway occlusion pressure, End-tidal Carbon-di-oxide and blood gas analysis with respect to baseline values. They concluded that sub anesthetic doses of Propofol, to maintain conscious sedation or light sleep have not been shown to cause respiratory depression.

Blounin RT et al. ${ }^{7}$ in their study, noted that profound depression of hypoxic ventilatory drive occurred during Propofol infusion (Conscious sedation), despite subjects ability to respond appropriately to verbal stimuli at all times. They concluded the importance of appropriate monitoring, supplementation of oxygen enriched air, ability to provide airway support and positive pressure ventilation when Propofol is used for conscious sedation.

Alexander $\mathrm{CM}$ et al. ${ }^{8}$ in their study, concluded that sedative doses of Midazolam depresses hypoxic ventilatory response and attenuates the hyperpnea and tachycardia associated with hypoxemia. They suggested that sedation with Midazolam should be accompanied by continuous monitoring of arterial oxygen saturation and supplemental oxygen.

Lordan JT et al. ${ }^{9}$ in their study concluded Propofol sedation for ERCP carried out in the presence of an anesthetist is safe and may improve procedural completion rates

Norton JR et al. ${ }^{10}$ in their study concluded Upper airway obstruction (UAO) during sedation can often cause clinically significant adverse events. Direct comparison of different drugs propensities for UAO may improve selection of appropriate sedating agents. At the mild to moderate level of sedation studied, Midazolam and Propofol sedation resulted in the same propensity for UAO. In a group of healthy subjects, there was a considerable range of negative pressures required to cause UAO.

Sanchez-Izquierdo-Riera JA, et al. ${ }^{11}$ in their study confirmed the safety and efficacy of midazolam and propofol, alone or in combination, in the prolonged sedation of a homogeneous group of severe trauma patients, particularly in patients with head trauma. The propofol group had shorter wake-up times and higher triglyceride levels.

Rahman NH, et al. ${ }^{12}$ in this study aimed to determine the effectiveness of Propofol as an alternative agent for procedural sedation and analgesia (PSA) in the emergency department (ED) and to make a comparison between two different sedative (Propofol vs Midazolam) drugs used in combination with Fentanyl. Both Propofol and Midazolam given at the recommended doses were equally safe and effective for PSA in the ED. The Propofol group was discharged much earlier than to the Midazolam group.

Wagner HJ et al. ${ }^{13}$ in their study concluded Propofol causes less respiratory depression than Midazolam for equivalent sedation and anxiolysis in patients undergoing PTA.

Khurana $\mathrm{P}$ et al. ${ }^{14}$ in their study showed that Effective sedation is an essential for regional techniques too. This study compares Midazolam and Propofol in terms of onset and recovery from sedation, dosage and side effects of both the drugs using Bispectral Index monitoring. Ninety-eight patients were randomly divided into two groups, one group received Midazolam infusion while the other received Propofol infusion until BIS reached 75. They concluded that both Midazolam and Propofol are effective sedatives, but onset and offset was quicker with Propofol, while Midazolam was more cardio stable.

Uri $\mathrm{O}$ et al. ${ }^{15}$ in their study compared the recovery time, the total sedation time, and the adverse events of procedural sedation and analgesia induced with propofol as compared with Midazolam/ Ketamine. The use of propofol for an orthopedic procedure requiring sedation in the emergency department expedites patient management and saves time in comparison with the use of Midazolam/Ketamine.

Carlsson $\mathrm{U}$ et al. ${ }^{16}$ : The aim of this study was to compare the quality of sedation provided by Midazolam and Propofol under controlled conditions. Compared to Midazolam, Propofol facilitated gastroscopy to a greater extent. However, due to its narrower therapeutic range, Propofol is the more demanding agent to administer, thus making it less universally applicable than Midazolam. 
addition of Alfentanil and or Propofol to Midazolam was evaluated with regard to hemodynamic variables, respiratory rate, pain, anxiety, sedation, postoperative recovery and patient satisfaction. They concluded that, the addition of Alfentanil to Midazolam is advantageous in providing sedation for insertion of intraocular block.

Chamorro $\mathrm{C}$ et al. ${ }^{18}$ in a study To compare the effectiveness, characteristics, duration of action, hemodynamic and biochemical effects, and side effects of Propofol and Midazolam used for continuous intravenous sedation of ventilated critically ill patients in a Multicenter, prospective, randomized, nonblinded study. In this population of critically ill patients, Propofol is an effective and safe alternative for sedation, with some advantages, such as short duration of action and high effectiveness over the conventional regimen with benzodiazepines and opiates.

Smith I et al. ${ }^{19}$ found no fall in arterial oxygen saturation of less than $95 \%$. All patients were given supplemental oxygen at $4 \mathrm{~L} / \mathrm{min}$ via nasal prongs throughout the procedure.

\section{CONCLUSION}

Propofol (Group I) and Midazolam (Group II) were compared as sedative agents for conscious sedation in 60 ASA grade I and II patients undergoing tympanoplasty and mastoidectomy under local anesthetic infiltration. All the patients in both the groups were comparable with respect to age and weight. All patients in both groups received injection fentanyl as an analgesic to supplement local anesthetic infiltration. All the patients in the both the groups were given supplemental oxygen via nasal prongs at flow rate $4 \mathrm{~L} / \mathrm{min}$. Both the drugs have stable respiratory and cardiovascular effects when used in a dosage required to produce conscious sedation along with supplemental oxygen.

\section{Source of Support: Nil}

Conflict of Interest: None declared.

\section{REFERENCES:}

1. Donlon JV and Moss J. Plasma Catecholamine levels during local anaesthsia for cataract operations. Anaesthesialogy. 1979;51:471.

2. Mackenzie N and Grant IS. Propofol for intravenous sedation. Anesthesia. 1987;42(1):3-6.

3. Fanard L, Van Steenberge A, Demeire X. Comparison between Propofol and Midazolam as sedative agents for surgery under local anaesthesia. Anaesthesia. 1988;43 (suppl.):87-89.

4. Wilson E, David A, Mackenzie N and Grant IS. Sedation during spinal anesthesia: Wilson E, David A, Mackenzie N and Grant IS. Sedation during spinal anesthesia:
Comparison of Propofol and Midazolam. British Journal of Anesthesia. 1990;64:48-52. . Crawford M, Pollock J, Anderson K, Glavin RJ. Comparison of Midazolam and Propofol in outpatient bronchoscopy. British Journal of Anesthesia. 1993;70:419-422.

6. Rosa G, Conti G, Gasparetto A. Effects of low dose of Propofol administration on central respiratory drive, gas exchange and respiratory pattern. Acta Anesthesiol Scand 1992;36:128-131.

7. Blounin RT, Seifert HA, Conard PF. Propofol depresses hypoxic ventilatory response/drive during conscious sedation and isohypercapnea. Anesthesiology. 1993;79:1177-1182.

8. Alexander CM, Gross JB. Sedative doses of midazolam depress hypoxic ventilatory responses in humans. Anaesth Analg. 1988;67(4):377-382.

9. Lordan JT, Woods J, Keeling P, Paterson IM. A retrospective analysis of benzodiazepine sedation vs. propofol anaesthesia in 252 patients undergoing endoscopic retrograde cholangiopancreatography. Endoscopy. 2000 Sep;32(9):677-82.

10. Norton JR, Ward DS, Karan S, Voter WA, Palmer L, Varlese A, Rackovsky O, Bailey P. Differences between midazolam and propofol sedation on upper airway collapsibility using dynamic negative airway pressure. Anesth Analg. 1998 Jun;86(6):1219-24.

11. Sanchez-Izquierdo-Riera JA, Caballero-Cubedo RE, Perez-Vela JL, Ambros-Checa A, Cantalapiedra-Santiago JA, Alted-Lopez E. Propofol versus midazolam: safety and efficacy for sedating the severe trauma patient. Vasc Interv Radiol. 1996 Sepefficacy for sedating the severe trauma patient. Vasc Interv Radiol. 1996 Sep-
Oct;7(5):673-80.

12. Rahman NH, Hashim A. The use of propofol for procedural sedation and analgesia in the emergency department: a comparison with midazolam. Anesthesiology. 2006 Jun;104(6): 1155-64.

13. Wagner HJ, Nowacki J, Klose KJ. Propofol versus midazolam for sedation during percutaneous transluminal angioplasty. J Bone Joint Surg Am. 2011 Dec 21;93(24):2255-62.

14. Khurana P, Agarwal A, Verma RK, and Gupta PK. Comparison of Midazolam and Propofol for BIS-Guided Sedation during Regional Anaesthesia. Indian J Anaesth. 2009 December; 53(6):662-666.

15. Uri O, Behrbalk E, Haim A, Kaufman E, Halpern P. Procedural sedation with propofol for painful orthopaedic manipulation in the emergency department expedites patient management compared with a midazolam/ketamine regimen: a randomized prospective study. J Bone Joint Surg Am. 2011;93(24):2255-2262. doi:10.2106/JBJS.J.01307

16. Carlsson U, Grattidge P. Sedation for upper gastrointestinal endoscopy: a comparative study of propofol and midazolam. Endoscopy. 1995;27(3):240-243. doi:10.1055/s$2007-1005678$

17. Fiona E. McHardy, Joanne Fortier, Frances Chung, Ananthan Krishnathas, Scott I. Marshall. A comparison of midazolam, alfentanil and propofol for sedation in oupatient intraocular surgery. Canadian Journal of Anaesthesia. 2012;47(3):211-214.

18. Chamorro C, de Latorre FJ, Montero A, Sánchez-Izquierdo JA, Jareño A, Moreno JA, Gonzalez E, Barrios M, Carpintero JL, Martín-Santos F, Otero B, Ginestal R. Comparative study of propofol versus midazolam in the sedation of critically ill patients: results of a prospective, randomized, multicenter trial. Crit Care Med. 1996 Jun;24(6):932-9.

19. Smith I, Monk TG, White PF, Ding Y. Propofol infusion during regional anesthesia: sedative, amnestic, and anxiolytic properties. Anesth Analg. 1994;79(2):313-319. doi:10.1213/00000539-199408000-00020 